\title{
Evaluation of the Maximum Interconnected Capacity in a Primary Feeder after Distribution Generation Connection
}

\author{
Wei-Tzer HUANG \\ Department of Industrial Education and Technology \\ National Changhua University of Education, No.2, Shi-Da \\ Road \\ Changhua City 50007, Taiwan, R.O.C
}

Kai-Chao YAO

Department of Industrial Education and Technology

National Changhua University of Education, No.2, Shi-Da

Road

Changhua City 50007, Taiwan, R.O.C

\section{Chun-Ching WU}

Department of Industrial Education and Technology

National Changhua University of Education, No.2, Shi-Da

Road

Changhua City 50007, Taiwan, R.O.C

\author{
Chih-Hui LO \\ Department of Industrial Education and Technology \\ National Changhua University of Education, No.2, Shi-Da \\ Road \\ Changhua City 50007, Taiwan, R.O.C \\ Wen-Chih YANG \\ Department of Electrical Engineering \\ Taipei Chengshih University of Science and Technology \\ R.O.C
}

\author{
Yu-Hsin HUANG \\ Department of Transmission Line and Substation Projects \\ Central Region Construction Office, Taiwan Power Company \\ Taiwan, R.O.C
}

\begin{abstract}
This paper aims to evaluate the maximum interconnected capacity of the distributed generation(DG), which been interconnected into the distribution feeders. The $\pm 2.5 \%$ voltage derivation limit of the Taipower interconnected guides are adopted for evaluating the maximum interconnected capacity of DG, and the unbalanced power flow program is used to solve for the bus voltage profiles before and after the DG interconnected into a primary feeder. The IEEE 13-Bus feeder is modified as a sample system. The simulation scenariosinclude the individual phase and three-phase connections between the DG and the primary feeder. The outcomes demonstrate that the maximum interconnected capacity of DG is dependent on the short-circuit capacity, connection location, load demand, and voltage variation limit.
\end{abstract}

Keywords-distributed generation; maximum interconnected capacity; power flow; voltage variation

\section{INTRODUCTION}

Recently,because of the global warming problem, to reduceemissions ofthe majorindustrialized countriesis the major task toachievegreenhousegas reductiontargets, the targetin2050 is to reduceglobal emissions by48 billion tonsofCO ${ }_{2}$. Wherethe majortechnologiesfor the target includerenewable energy development,improving power generation efficiency, carbon capture and storage, nuclear power generation, andimproving energyend use efficiency[12].Therefore, Taiwan governmentisto promoterenewable energygeneration systems, in order to reducedependenceonfossil fuelsandtheenvironmental impact ofglobal warming. Additionally, European Smart Grids Technology Platform has planed theoutline of the European electricitynetworkdevelopment vision towards2020, the outlines indicated the development of the low pollutionlarge centralizedpower plants, as well asdistributed energy resource(DERs), which includes DG and energy storage devices, such as wind power, solar power, biomass, ocean energy, hydraulic, and fuel fell technologies[3]. These energies are renewable, clean, and zero emissions. Consequently, the penetration of renewable energy generation systems will both provide the clean electricity energy and improve the power system efficiency; furthermore, it can mitigateglobal warmingphenomenon.

The DG can be divided intorenewableandnonrenewableenergy powergeneration. It is expect that the high penetration of DG will impact the planning, operations, and control of power distribution systems. Hence, some rules or guides for DG interconnected with electric power systems are developed, such as IEEE Std. 1547 [4], California Electric Rule 21 [5], and Taipower interconnected guide [6], etc. In which the voltage variation is one of the key factors that affect the DG connected to distribution feeders [7]. In this paper, according to the $\pm 2.5 \%$ voltage variation limit of the Taipower interconnected guide, the maximum interconnected capacity in a primary feeder after the DG connection is analyzed. 


\section{PROBLEM DESCRIPTION}

\section{A. System Structure}

The IEEE 13-Bus test feeder is used as a sample system for the analysis of maximum apparent power injection in a primary feeder after a DG connection, as shown in figure 1 . And the parameters for power flow analysis to evaluate the voltage variation after the DG interconnected to the primary feeder are shown in [8].There are several candidate interconnected locations of the DG, and the maximum interconnected capacity of the DG in each location is different, which is limited by the voltage variation. In this paper, the interconnected location is assumed to connect to bus 680; this bus is located at the feeder end and the maximum interconnected capacity is the least among others.

\section{B. Description of the Simulation Cases}

The OpenDSS[9] is used to execute the three-phase power analysis, and then the voltage variations after the DG connected to a primary feeder are evaluated. The simulation cases are described in Table 1.The simulation scenarios covers all the loading conditions that include $100 \%, 80 \%, 60 \%, 40 \%$, and $20 \%$ of the full load, and these scenarios are representative.

TABLE I. DESCRIPTION OF THE SIMULATION CASES.

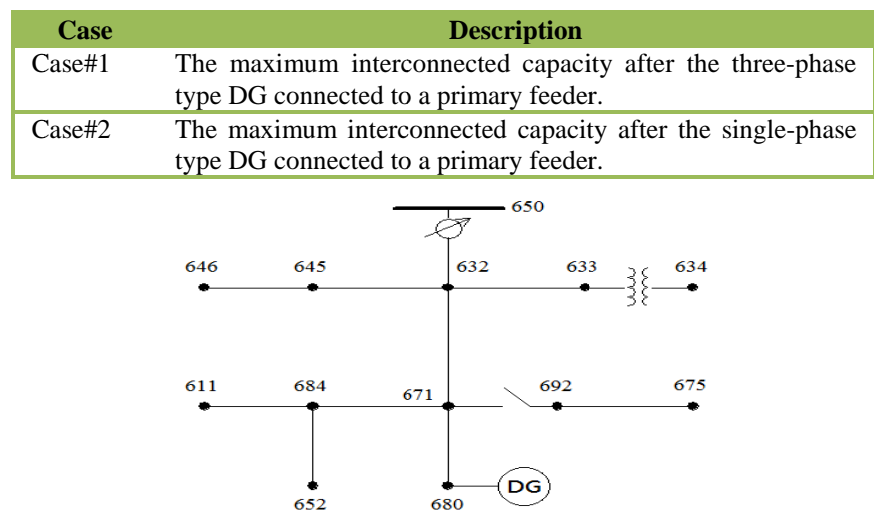

FIGURE I.IEEE 13-BUS FEEDER WITH DG.

\section{DISCUSSIONS AND ANALYSIS OF THE SIMULATION RESULTS}

\section{A. Voltage Variation Formula}

According to the Taipower interconnected guide, the voltage variation at the connection point is limited to $\pm 2.5 \%$. Therefore, the formula of steady-state voltage variation after the DG interconnected to the primary feeder is shown in (1).

$$
\mathrm{VD} \%=\frac{\left|V_{\mathrm{DG} \text { (with) }}\right|-\left|\mathrm{V}_{\mathrm{DG}(\mathrm{w} / \mathrm{o})}\right|}{\left|\mathrm{V}_{\mathrm{DG}(\mathrm{w} / \mathrm{o})}\right|} \times 100 \%
$$

Where the $\left|V_{D G(\text { with) }}\right|$ represents the voltage magnitude at the connection point after the DG connection, and the $\left|V_{D G(w / o)}\right|$ denotes the voltage magnitude at the connection point before the DG connection. In the followings, the voltage variations in this paper are calculated by (1).

\section{B. Discussions of the Case\#1 Simulation Results}

The simulation result of maximum interconnected capacity of three-phase type DG is shown in figure 2, and the voltage variation in phase $\mathrm{A}, \mathrm{B}$, and $\mathrm{C}$ are shown in figure 3,4 , and 5 , respectively. It is obvious that the load increased will result in the less maximum interconnected capacity of the DG. Besides, the maximum interconnected capacity of the DG is determined by the phase, which reached to the upper limited of the voltage variation. For instant, the maximum interconnected capacity of the DG is limited by the voltage variation in phase $\mathrm{A}$ in this simulation condition, because of the voltage variation in phase $\mathrm{A}$ is reach to $2.5 \%$, although phase $\mathrm{B}$ and $\mathrm{C}$ are still below $2.5 \%$.

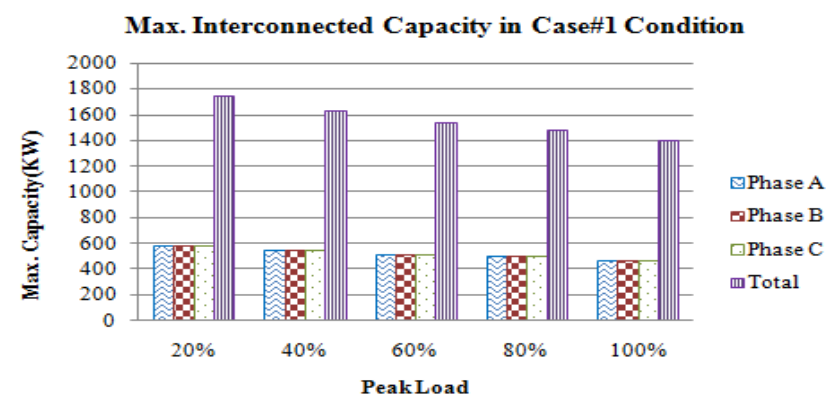

FIGURE II. THE MAXIMUM INTERCONNECTED CAPACITY IN EACH PHASE OF CASE\#1.

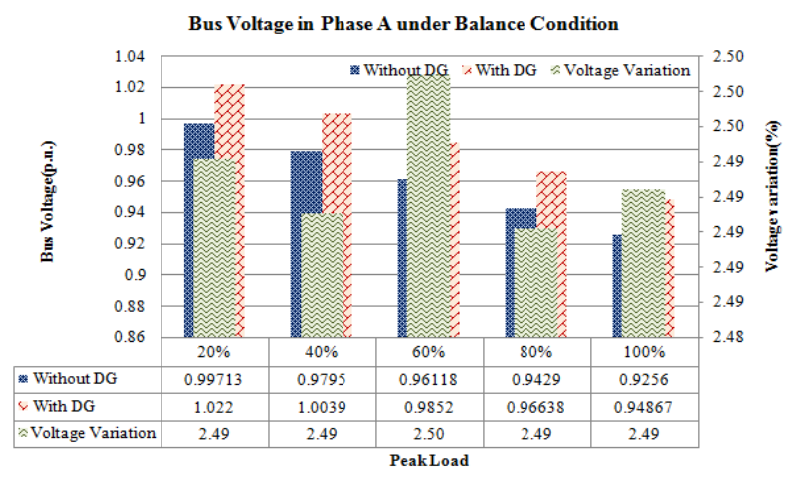

FIGURE III. THE VOLTAGE VARIATION IN PHASE A OF CASE\#1.

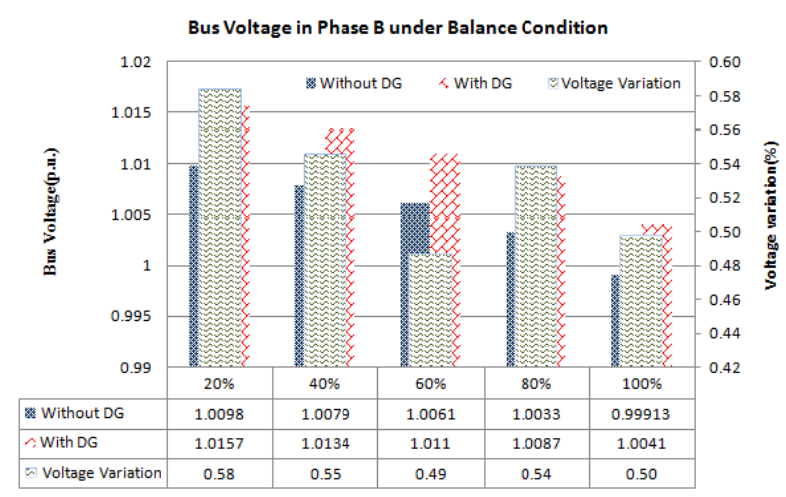

FIGURE IV. THE VOLTAGE VARIATION IN PHASE B OF CASE\#1. 


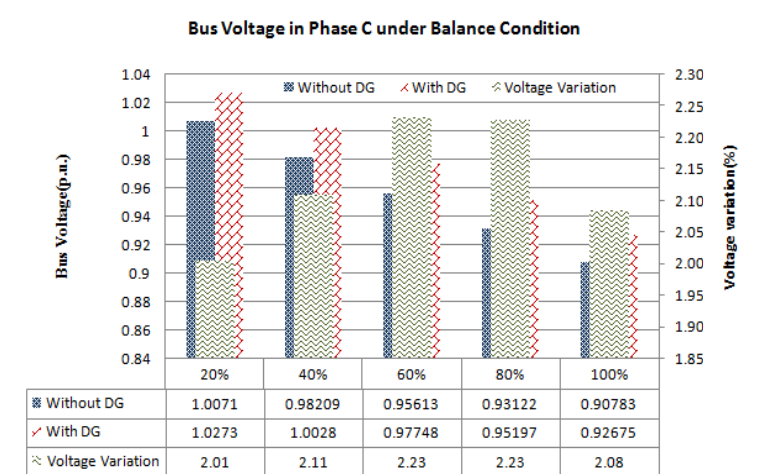

FIGURE V.

THE VOLTAGE VARIATION IN PHASE C OF CASE\#1.

\section{Discussions of the Case\#2 Simulation Results}

In this case, the simulation result of maximum interconnected capacity of single-phase type DG is shown in figure 6; besides, the voltage variation in phase $\mathrm{A}, \mathrm{B}$, and $\mathrm{C}$ are shown in figure 7,8 , and 9 , respectively. This simulation results also demonstrate that the load increased will result in the less maximum interconnected capacity of the DG. Similarly, the maximum interconnected capacity of the DG is determined by the phase, which reached to the upper limited of the voltage variation. It is clear that the simulation results in this case is different from that of case\#1. The maximum interconnected capacity in each phase are not the same due to the single-phase type DG connected to individual phase, and the maximum interconnected capacity in phase $\mathrm{B}$ and $\mathrm{C}$ are larger than that of case\#1. Consequently, the total injected apparent power at the connection point is larger than that of case\#1.

Max. Interconnected Capacity in Case\#2 Condition

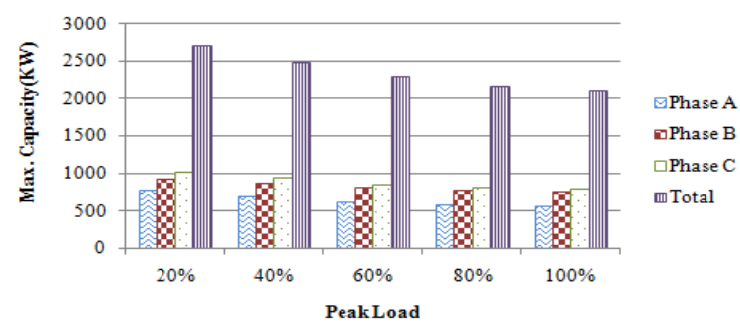

FIGURE VI. THE MAXIMUM INTERCONNECTED CAPACITY IN EACH PHASE OF CASE\#2.

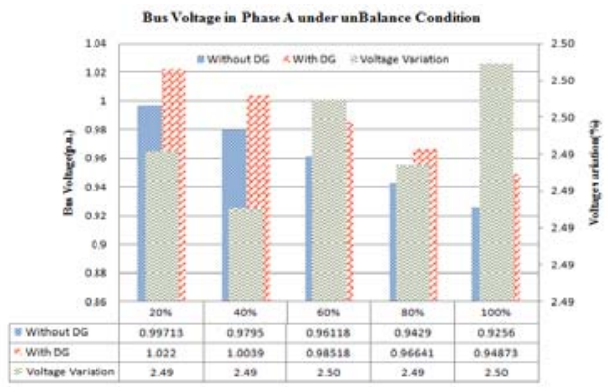

FIGURE VII.

THE VOLTAGE VARIATION IN PHASE A OF CASE\#2.

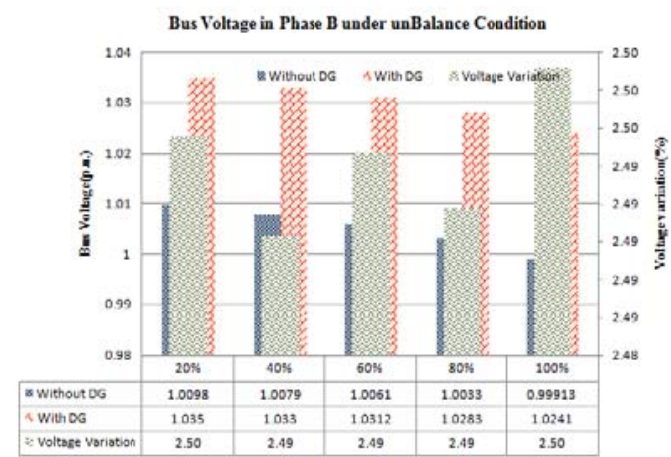

FIGURE VIII. THE VOLTAGE VARIATION IN PHASE B OF CASE\#2.

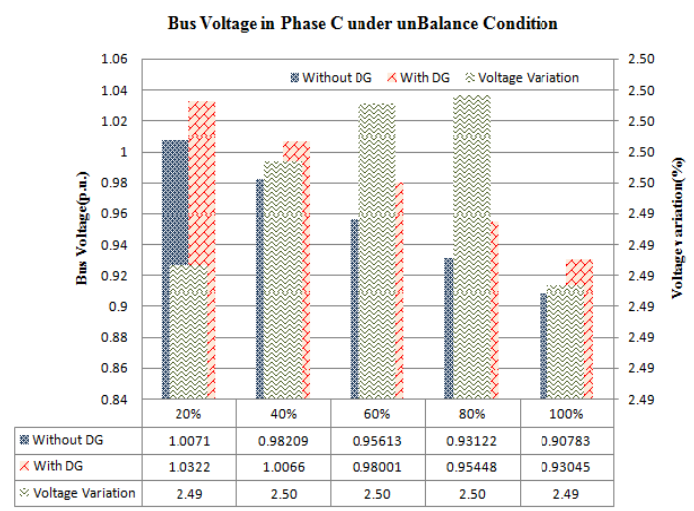

FIGURE IX. THE VOLTAGE VARIATION IN PHASE C OF CASE\#2.

\section{CONCLUSION}

In this paper, the maximum interconnected capacityin a primary feeder after DG connection is evaluated according to the Taipower interconnected guide. The unbalanced power flow program is used to solve for the bus voltage profiles before and after the single-phase and three-phase type DGs interconnected into the IEEE 13-Bus feeder. The simulationresults demonstrate that the maximum interconnected capacity of DG at the connection point is dependent on the loadingconditions, and voltage variation limit in this paper.

\section{ACKNOWLEDGEMENT}

This study was funded by a grant provided by the ministry of science and technology, Taiwan, under the grant number MOST 103-2221-E-018-020.

\section{REFERENCE}

[1] Intergovernmental Panel on Climate Change Fourth Assessment Report. Chapter 1: Historical overview of climate change science.

[2] http://www.ncu.edu.tw/ ncume_ee/tlyeh/shuan/greenhousegas.htm.

[3] http://www.wbdg.org/resources/der.php.

[4] Energy Policy \& Program http://www.moeaboe.gov.tw/.

[5] IEEE Std. 1547, Standard for Interconnecting Distributed Resources with Electric Power Systems.

[6] The interconnection guide for renewable energy generation system of Taipower http://www.taipower.com.tw/.

[7] W. T. Huang, K. C. Yao, C. C. Wu, S. W. Wang, S. A. Yin, “OpenDSS 
Framework for System Impact Analysis of a $406 \mathrm{~kW}$ Photovoltaic System Interconnected to a Distribution Feeder,” ICIC Express LettersAn International Journal of Research and Survey, Vol. 9, No. 2, pp. 343349, February, 2015.

[8] http://ewh.ieee.org/soc/pes/dsacom/testfeeders/

[9] Roger C.Dugan, "Reference Guide the Open Distribution System Simulator (OpenDSS),”EPRI, November 2012. 